\title{
ABTS-Modified Silica Nanoparticles as Laccase Mediators for Decolorization of Indigo Carmine Dye
}

\author{
Youxun Liu, Mingyang Yan, Yuanyuan Geng, and Juan Huang \\ School of Basic Medical Sciences, Xinxiang Medical University, Jinsui Avenue 601, Xinxiang, Henan 453003, China \\ Correspondence should be addressed to Juan Huang; huangjuan@xxmu.edu.cn
}

Received 1 October 2015; Revised 29 November 2015; Accepted 13 December 2015

Academic Editor: Maria P. Robalo

Copyright (C) 2015 Youxun Liu et al. This is an open access article distributed under the Creative Commons Attribution License, which permits unrestricted use, distribution, and reproduction in any medium, provided the original work is properly cited.

\begin{abstract}
Efficient reuse and regeneration of spent mediators are highly desired for many of the laccases' biotechnology applications. This investigation demonstrates that a redox mediator 2,2' -azino-bis-(3-ethylbenzothiazoline)-6-sulfonic acid (ABTS) covalently attached to silica nanoparticles (SNPs) effectively mediated dye decolorization catalyzed by laccase. Characteristics of ABTSmodified silica nanoparticles (ABTS-SNPs) were researched by scanning electron microscopy and Fourier-transformed infrared spectroscopy. When ABTS and ABTS-SNPs were used as laccase mediators, the decolorization yields of 96 and $95 \%$ were, respectively, obtained for indigo carmine dye. The results suggest that ABTS immobilized on SNPs can be used as laccase mediators as they retain almost the same efficiency as the free ABTS. The oxidized ABTS-SNPs were regenerated by their reduction reaction with ascorbic acid. Decolorization efficiency of regenerated ABTS-SNPs and their initial forms were found to be almost equivalent. Six reuse cycles for spent ABTS-SNPs were run for the treatment of indigo carmine, providing decolorization yields of 96-77\%. Compared with free mediator, the immobilized mediators have the advantage of being easily recovered, regenerated, and reused making the whole process environmentally friendly.
\end{abstract}

\section{Introduction}

It is known that laccase (EC 1.10.3.2, p-diphenol: dioxygen oxidoreductases) belongs to the family of the multicopper oxidases [1, 2]. It can oxidize various organic substrates including phenols and arylamines, even some inorganic compounds. In catalytic reactions of laccase, oxygen acts as the terminal electron acceptor with water as the only by-product $[3,4]$. Due to their broad substrate specificity, laccases play a major role in a number of biotechnological and industrial applications $[5,6]$. In general, the potential of fugal laccase varies within $430-780 \mathrm{mV}$ [2]. The laccase cannot oxidize these substrates whose redox potential exceeds $800 \mathrm{mV}$. Interestingly, when several chemicals called as mediators such as ABTS are added into catalytic reactions, laccase is able to oxidize those substrates with high redox potential like nonphenolics $[7,8]$. Therefore, application range of laccase is further expanded by laccase-mediator systems (LMSs). It has been reported that for a number of industrial processes mediated by laccases, redox mediators, are required in order to oxide complex substrates [7]. LMSs are known to catalyze diverse reactions, and in wastewater treatment they are used to detoxify or remove xenobiotic compounds [9-12]. ABTS and 1-hydroxybenzotriazole have been found to be efficient laccase mediators in the decolorization of recalcitrant dyes $[13,14]$. When ABTS is used as a mediator, redox interaction with laccase could produce in situ two reactive intermediates from ABTS, namely, $\mathrm{ABTS}^{+\bullet}$ or $\mathrm{ABTS}^{2+}[8]$. However, it has been reported that their degradation by-products formed in situ by hydrolysis during the laccase-ABTS reactions may also be responsible for the observed oxidation of nonphenolics [8]. The redox potential of the laccase-ABTS system is around $885 \mathrm{mv}$ which may be enough to oxidize some dyes [7], but the efficiency of substrate degradation will depend on the redox potential of used laccase, mediator, and substrate.

Many mediators used in these applications are soluble in the reaction medium. There are, however, several disadvantages of using dissolved mediators including their interferences during product purification, their limited reusability, and their cost-intensive removal from wastewater. Numerous 


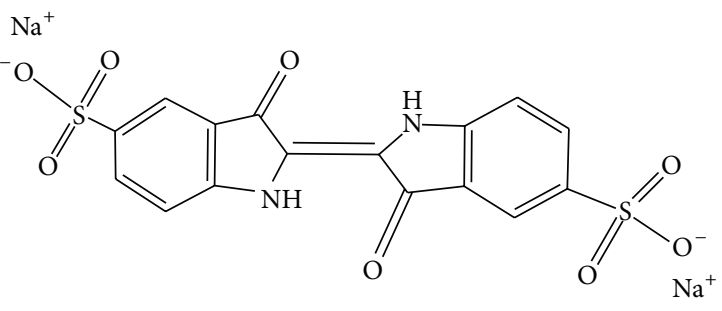

FIGURE 1: Molecular structure of indigo carmine. ways of laccase immobilization are presented in the literature [15-17], whereas the accounts of immobilization of mediators are scarce. Recently, the electrode modified with ABTS polymer exhibited electrocatalytic activity towards dioxygen when immersed in laccase solution [18]. The fungal laccase has previously been successfully entrapped in poly-o-phenylenediamine matrix, which can mediate the enzymatic reaction [19]. Covalently attached 2,2,6,6tetramethylpiperidinel-oxyl to polyethylene glycol has also been successfully utilized as a laccase mediator for dye decolorization in a membrane reactor [20]. On the one hand, small molecule mediators noncovalently adsorbed to insoluble carriers lead to mediator leakage in use. On the other hand, polymers or films modified with molecule mediators ordinarily may result in formidable mass-transfer resistance to the laccase-catalyzed reactions. To circumvent these problems, mediators can be covalently attached to nanosized particles that significantly reduce the external resistance to mass transfer. Further, mediator-modified nanoparticles can be recovered easily for repeated use, after effectively mediating the reactions catalyzed by enzymes. Resulting from the ability of the dication $\mathrm{ABTS}^{2+}$ to undergo reversible oxidation to $\mathrm{ABTS}^{+}$radical, ABTS is considered as a one of the most efficient mediator of laccase [21-24]. It has been reported that laccase with ABTS is able to degrade various environmental contaminants $[8,25]$. Indigo carmine (Figure 1 ) is the most representative indigoid dye, and it is widely used as textile coloring agent [26]. It has been proved that the dye is carcinogenic and can lead to reproductive, developmental, neuron, and acute toxicity [27]. Thus, considering the toxicity of this dye, numerous attempts have been made to remove indigo carmine from wastewater [26, 27]. Because indigo carmine is not a typical substrate of laccase, the complete decolorization of this dye by laccase needs the help from a mediator. Therefore it was chosen as the model recalcitrant compound for carrying out decolorization reaction in this study.

In the present study, our goal was to utilize ABTS-modified silica nanoparticles (SNPs) as mediators for a laccasecatalyzed decolorization of indigo carmine dye. First, ABTS was covalently attached to SNPs to yield ABTS-immobilized SNPs (ABTS-SNPs), which were utilized as laccase mediators to decolorize indigo carmine dye. Secondly, these immobilized ABTS-SNPs were proved to be effective reusable mediators and easily recovered by centrifugation of the reaction medium.

\section{Materials and Methods}

2.1. Chemicals. ABTS and laccase (catalogue number 38429) were purchased from Sigma-Aldrich, USA. Indigo carmine (purity $\geq 96 \%$, MW 466.35) was obtained from Aladdin, China. The SNPs (catalogue number XF105, purity > 99\%) used in this study were milky white dispersion and purchased from purchased from Nanjing XFNANO Materials Tech Co., Ltd., China. The diameter of SNPs ranges between $10 \mathrm{~nm}$ and $50 \mathrm{~nm}$. All chemicals were used as received without further purification. Deionized water was used throughout the whole experiment.

\subsection{Preparation and Characteristics of Silica Nanoparticles} Modified with ABTS. The researchers have recently developed a procedure for the modification of the carbon nanotubes with residues of ABTS [28, 29]. By employing the same procedure, amino-functionalized SNPs were conjugated with ABTS. In brief, first, ABTS (ammonium salt) was converted into potassium salt by reaction with potassium tert-butoxide. Then, disulfonyl bromide was obtained by the reaction of potassium salt with triphenylphosphine/ $\mathrm{Br}_{2}$. Finally, ABTS was covalently bonded to SNPs by the disulfonyl bromide reacted with amino-functionalized SNPs (Scheme 1). The resulting samples were centrifuged and washed thoroughly several times with dimethyl sulfoxide, methanol, and distilled water, respectively, until unbounded species were completely removed. ABTS covalently attached to SNPs were obtained and resuspended in distilled water. The functional groups of SNPs, ABTS-SNPs, and ABTS were studied using Fourier transform infrared (FT-IR) spectroscopy (Bruker Optics Tensor 37) in the range $4000-450 \mathrm{~cm}^{-1}$ at a resolution of $2 \mathrm{~cm}^{-1}$. These samples were initially dried in drying oven and then were ground with $\mathrm{KBr}$, respectively. The mixture was molded into a disc, which was analyzed by FT-IR. According to elemental analysis, there were about $0.09 \% \mathrm{~S}$ in the ABTSSNPs; this meant that the amount of ABTS attached to SNPs was about $7 \mu \mathrm{mol} / \mathrm{g}$. The microstructure of ABTS-SNPs was characterized by a JEOL JSM-6700F field emission scanning electron microscope (SEM).

2.3. Dye Decolorization. The effect of $\mathrm{pH}$ on decolorization of indigo carmine $(20 \mathrm{mg} / \mathrm{L}$ dye $)$ by $3000 \mathrm{U} / \mathrm{L}$ laccase and $10 \mu \mathrm{M}$ ABTS at different $\mathrm{pH}$ ranging from 2.5 to $6(50 \mathrm{mM}$ sodium acetate buffer) was studied. Results from the preliminary experiments indicated that the optimal $\mathrm{pH}$ value was about 4.5, so decolorization experiments were performed using $20 \mathrm{mg} / \mathrm{L}$ dye, $3000 \mathrm{U} / \mathrm{L}$ laccase, and mediator $(10 \mathrm{~g} / \mathrm{L}$ for ABTS-SNPs containing $70 \mu \mathrm{M}$ ABTS or $70 \mu \mathrm{M}$ ABTS) at $\mathrm{pH}$ 4.5. After the addition of these samples into $5 \mathrm{~mL}$ centrifuge tube, the reaction mixture was incubated in $50 \mathrm{mM}$ sodium acetate buffer with gentle shaking at $150 \mathrm{rpm}$ at room temperature. Controls reactions were also carried out to study the decolorization efficiency by laccase without a mediator or with ABTS or ABTS-SNPs alone. The data presented are the average values of measurements from triplicate technical repeats. The absorption spectra of ABTS (70 $\mu \mathrm{M}$ ABTS) and indigo carmine $(20 \mathrm{mg} / \mathrm{L})$ in $50 \mathrm{mM}$ sodium acetate buffer at 


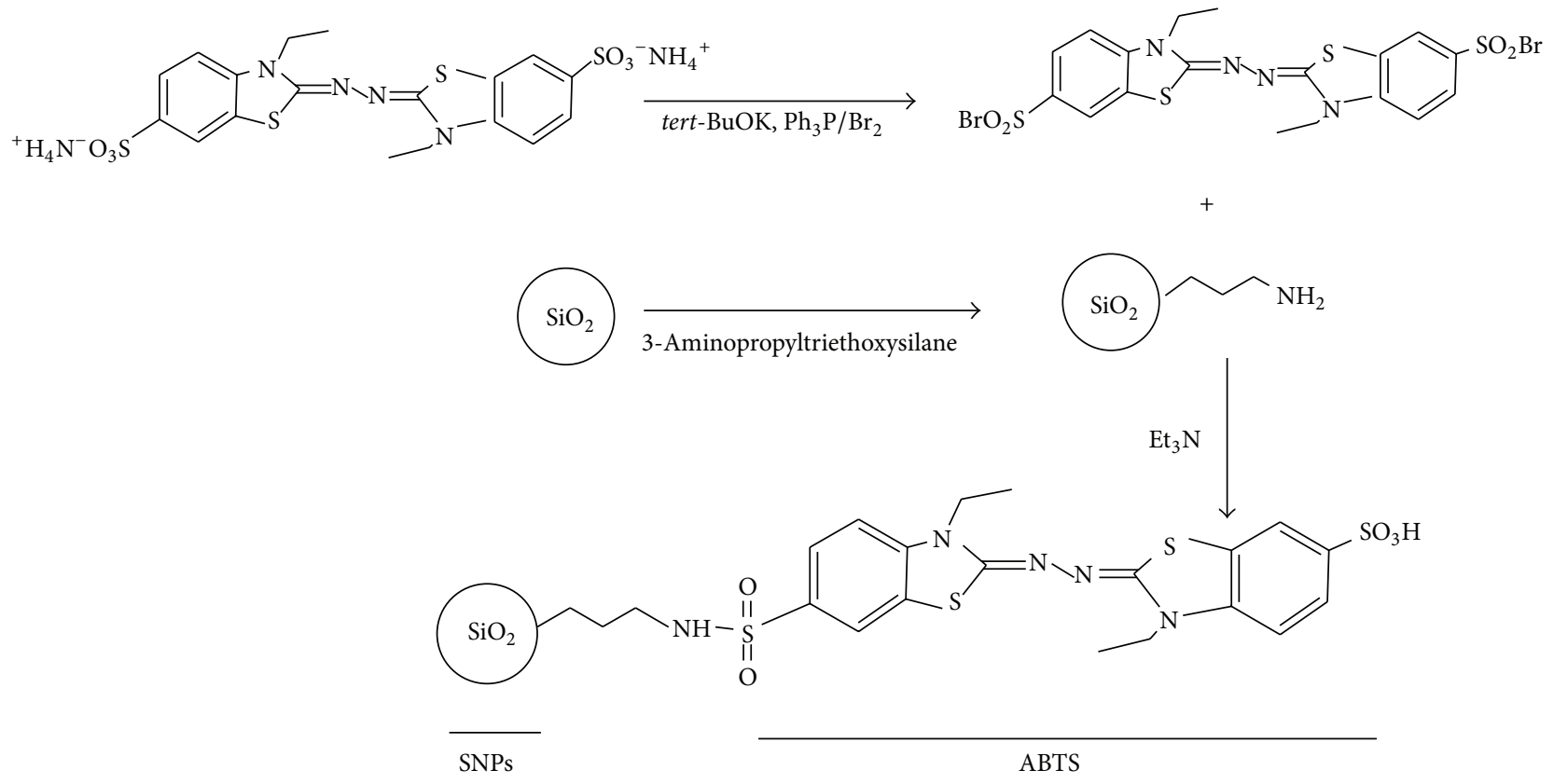

SCHEME 1: Structure of dominating SNP modifications obtained by the route for covalent attachment of ABTS.

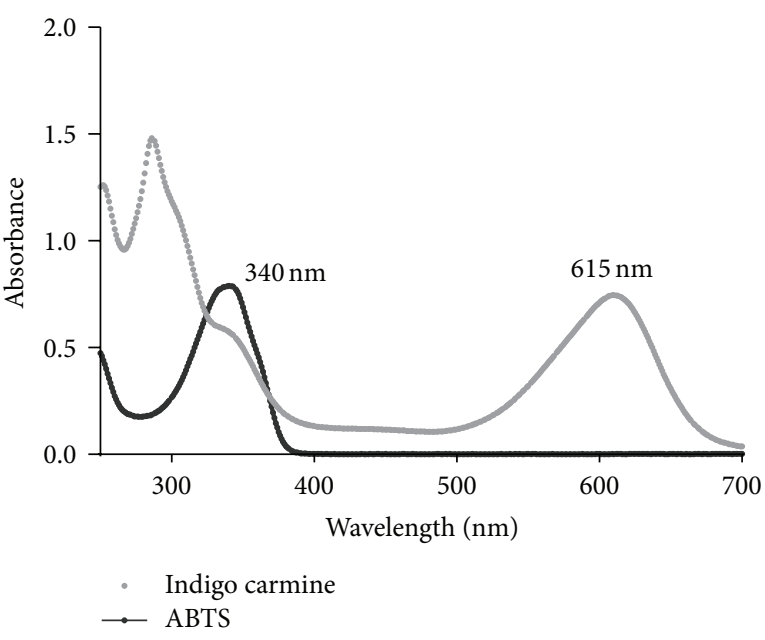

FIGURE 2: The absorption spectra of ABTS (70 $\mu \mathrm{M}$ ABTS) and indigo carmine $(20 \mathrm{mg} / \mathrm{L})$ in $50 \mathrm{mM}$ sodium acetate buffer at $\mathrm{pH} 4.5$.

pH 4.5 were shown in Figure 2, which indicated that ABTS has a major ultraviolet light absorption peak at $340 \mathrm{~nm}$ and indigo carmine has the absorbance peak at around $615 \mathrm{~nm}$. Decolorization was determined spectrophotometrically by monitoring the decrease in absorbance at the maximum wavelength of dye (around $615 \mathrm{~nm}$ ) using Shimadzu UV-2550 spectrophotometer. The percentage decolorization of a dye was calculated based on the formula: conversion $(\%)=\left(A_{0}-\right.$ $\left.A_{1}\right) / A_{0}$, where $A_{0}$ was the initial absorbance of the dye at its adsorption maximum and $A_{1}$ was its absorbance of the reaction mixture at the different reaction time.
2.4. Regeneration of the Oxidized ABTS-SNPs. After the decolorization reaction was complete, the oxidized ABTSSNPs were separated and then transferred into a $5 \mathrm{~mL}$ centrifuge tube containing $3.5 \mathrm{~mL}$ distilled water. With mixing, $10 \mu \mathrm{L}$ of $1 \mathrm{M}$ ascorbic acid was added. After shaking at $150 \mathrm{rpm}$ for $5 \mathrm{~min}$, the mixture was centrifuged for $2 \mathrm{~min}$ at $10000 \times \mathrm{g}$. The regenerated ABTS-SNPs were separated and washed thrice with $3 \mathrm{~mL}$ distilled water again.

2.5. Reusability of ABTS-SNPs. The recyclability of ABTSSNPs was assessed in a discontinuous decolorization reaction. Decolorization of indigo carmine $(20 \mathrm{mg} / \mathrm{L})$ were performed in a $5 \mathrm{~mL}$ centrifuge tube containing $3000 \mathrm{U} / \mathrm{L}$ of laccase and $10 \mathrm{~g} / \mathrm{L}$ ABTS-SNPs at $\mathrm{pH} 4.5$, shaking at $150 \mathrm{rpm}$ for $30 \mathrm{~min}$ at room temperature. At the end of every cycle, ABTS-SNPs were separated, regenerated, and washed thrice with $3 \mathrm{~mL}$ distilled water. Next, the ABTS-SNPs was added into a fresh reaction solution $(20 \mathrm{mg} / \mathrm{L}$ indigo carmine, $3000 \mathrm{U} / \mathrm{L}$ laccase, $\mathrm{pH}$ 4.5) to start a fresh cycle. The data presented are the average values of measurements from triplicate technical repeats.

\section{Results and Discussion}

3.1. Structure, Biochemical, and Physicochemical Characteristics of ABTS-SNPs. The chemical structure of ABTS-SNPs is presented in Scheme 1. Morphology of SNPs and ABTSSNPs, as obtained by SEM, is shown in Figures 3(a) and 3(b). The particles obtained after covalent attachment of ABTS on SNPs were found to be nanosized $(<50 \mathrm{~nm})$. Original SNPs were white, but the SNPs covalently attached to ABTS exhibited light yellow color (Figure 3(c)). After ABTS-SNPs 


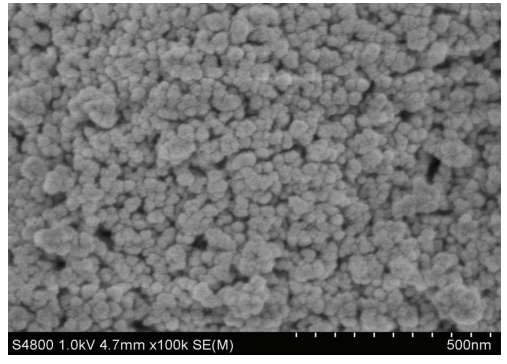

(a)

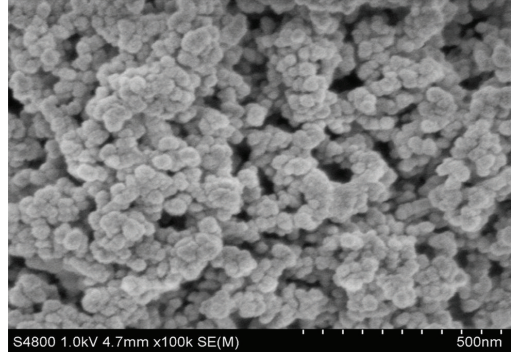

(b)

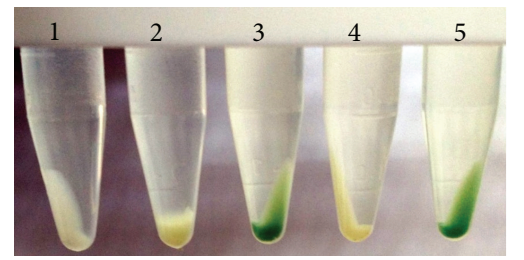

(c)

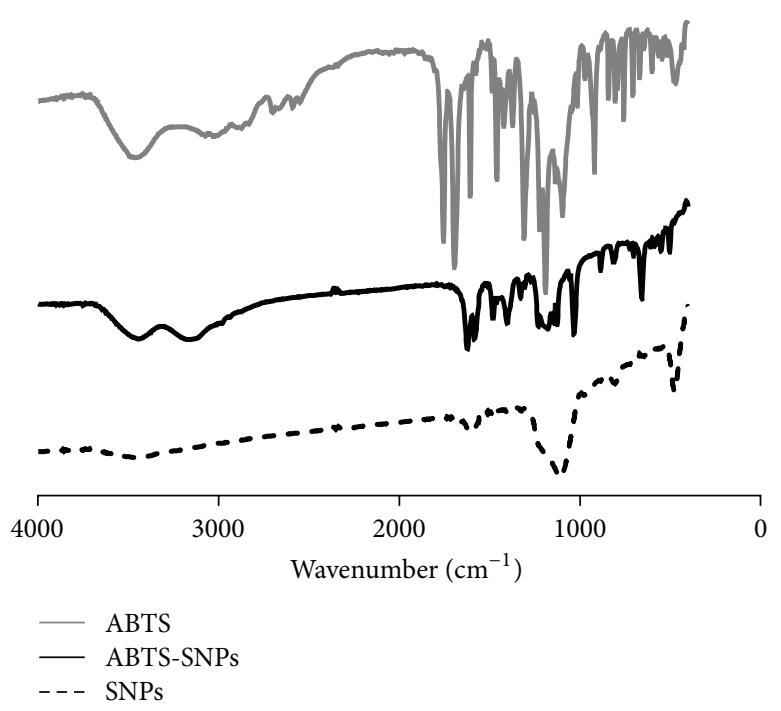

(d)

Figure 3: (a) SEM image of SNPs; (b) SEM image of ABTS-SNPs; (c) Tube 1, SNPs, Tube 2, SNPs covalently attached to ABTS, Tube 3, after reaction of ABTS-SNPs with laccase, Tube 4, regenerated ABTS-SNPs, Tube 5, after reaction of regenerated ABTS-SNPs with laccase, and (d) FT-IR spectra of ABTS, ABTS-SNPs, and SNPs.

were mixed with laccase for a few minutes, the mixture turned from light yellow to green. The color change in the reaction was attributed to the fact that ABTS molecules attached on the nanoparticle surface were oxidized to green $\mathrm{ABTS}^{+}$by laccase.

The comparison of transmission FT-IR spectral data for ABTS and ABTS-SNPs with those for the original SNPs is presented in Figure 3(d). In FT-IR spectra of ABTS-SNPs, the obvious new peak observed at $\sim 3400 \mathrm{~cm}^{-1}$ was due to the $\mathrm{N}$ $\mathrm{H}$ group stretching vibrations [30]. Other new peaks at about 1550 and $825 \mathrm{~cm}^{-1}$ in the FT-IR spectra of ABTS-SNPs were characteristic bands due to the aryl group [31]. Additionally, new strong peaks at 1360 and $1150 \mathrm{~cm}^{-1}$ were attributed to the characteristic absorptions of $\mathrm{SO}_{2}-\mathrm{N}$ [30]. These results clearly indicate that ABTS was covalently attached to the SNPs.
3.2. Dye Decolorization. The ABTS-SNPs were evaluated as laccase mediators for dye decolorization. The comparison of decolorization efficiency of laccase/ABTS-SNPs system with those for ABTS-SNPs, laccase, and laccase/ABTS system is shown in Figure 4. For ABTS-SNPs, only $\sim 4 \%$ of dye decolorization, respectively, was achieved in $15 \mathrm{~min}$. This decolorization was caused by the adsorption of ABTS-SNPs. For laccase alone, a dismal $\sim 3 \%$ decolorization was reached. The low decolorization rate was due to the fact that indigo carmine is not a typical phenol substrate of laccase. These results showed that removal of dye by nanoparticles or laccase was negligible. Almost complete decolorization (96\%) was achieved by laccase using ABTS as the mediator within $5 \mathrm{~min}$, while about $95 \%$ decolorization was achieved within $15 \mathrm{~min}$ using ABTS-SNPs as mediators. These results suggest that 


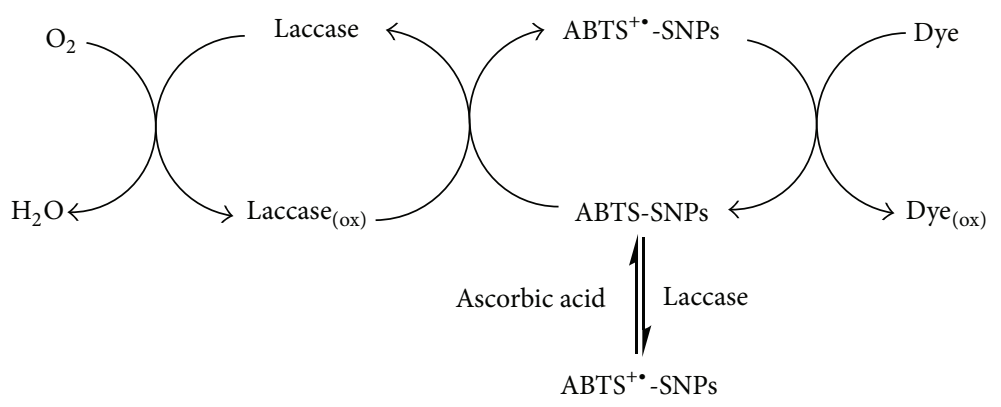

Scheme 2: The proposed catalytic cycle of decolorizing the dye by ABTS-SNPs mediated laccase oxidation.

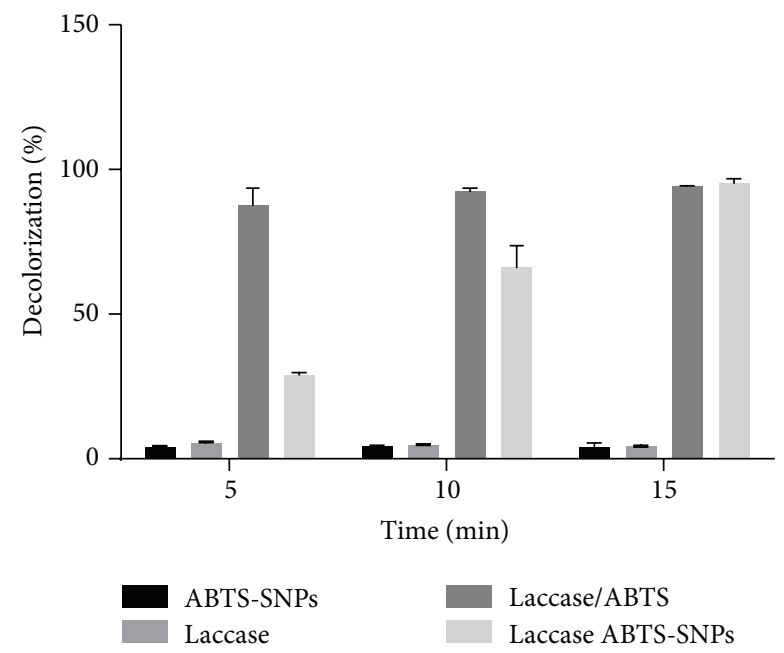

FIgURE 4: Decolorization of indigo carmine $(20 \mathrm{mg} / \mathrm{L})$ by ABTSSNPs $(10 \mathrm{~g} / \mathrm{L}$ containing $70 \mu \mathrm{M}$ ABTS), laccase (3000 U/L), laccase/ ABTS-SNPs, and laccase/ABTS $(70 \mu \mathrm{M}$ ABTS $)$ in $50 \mathrm{mM}$ sodium acetate buffer at $\mathrm{pH} 4.5$ with shaking at $150 \mathrm{rpm}$ at room temperature.

ABTS immobilized on SNPs can be used as an efficient mediator of laccase for decolorization in a manner similar to free ABTS. Even though the decolorization rate is slower for ABTS-SNPs than for the free mediator, the immobilized mediator has the advantage of being easily recovered from the reaction system.

3.3. Regeneration and Catalytic Cycle Mechanism of ABTSSNPS. In the case of laccase, the role of mediators in an enzymatic oxidation has been already described by several authors [7]. First, ABTS covalently attached to SNPs is converted into $\mathrm{ABTS}^{+}$cation radical by the enzymatic reaction. Subsequently, the $\mathrm{ABTS}^{+\bullet}$ cation radical takes part in nonenzymatic reactions with dyes which are not oxidizable by laccases alone. Simultaneously, the $\mathrm{ABTS}^{+\bullet}$ is reduced to its original form (ABTS) by the dye to be oxidized, and thus one catalytic cycle is completed. At the end of all catalytic cycle, the dye molecules are completely decolorized by oxidation and ABTS molecules are oxidized to $\mathrm{ABTS}^{+\bullet}$ by laccase again. Moreover, $\mathrm{ABTS}^{+\bullet}$ can be reduced by some strong reducing regents [23]. In our case, $\mathrm{ABTS}^{+\bullet}$-SNPs were reduced with

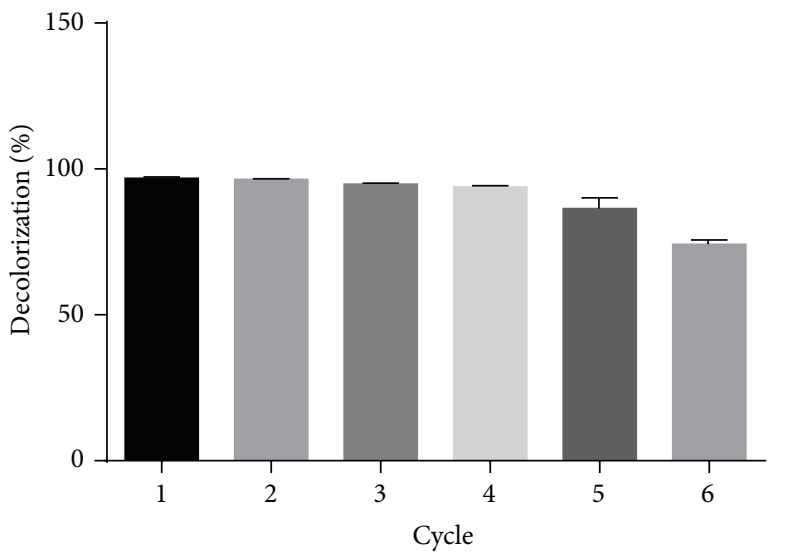

FIgURE 5: Reusability of ABTS-SNPs (10 g/L) in six successive cycles using $3000 \mathrm{U} / \mathrm{L}$ of laccase, and $20 \mathrm{mg} / \mathrm{L}$ of indigo carmine at $\mathrm{pH} 4.5$ with shaking at $150 \mathrm{rpm}$ for $30 \mathrm{~min}$ at room temperature.

ascorbic acid resulting in regeneration of ABTS-SNPs as shown in Scheme 2.

As shown in Figure 3(c), after the regeneration process, the oxidized ABTS-SNPs turned from green to light yellow-the original color of the initial ABTS-SNPs. Further, the regenerated ABTS-SNPs can be oxidized by laccase again. Decolorization efficiency of regenerated ABTS-SNPs as mediators was $93.5 \%$, which was almost the same as that of initial ABTS-SNPs ( $\sim 95 \%$ decolorization). The results show that ABTS-SNPs after use can be recovered and reused as efficient mediators for decolorization similar to original ABTS-SNPs.

3.4. Reusability. From the economic point of view, reusability of immobilized mediator plays a key role when LMSs will be used on a large scale for industrial applications [32]. The reusability of ABTS-SNPs was investigated for up to 6 cycles (Figure 5). When the reaction time was set to $30 \mathrm{~min}$, which proved to be sufficient for almost complete decolorization, comparably high decolorization yields were obtained in 4 subsequent runs using the same recovered and regenerated ABTS-SNPs. Approximately 77\% decolorization could be maintained after 6 cycles. A slight decrease in decolorization efficiency was observed, which was attributed to partial destruction of ABTS-SNPs during the reaction 
and/or the loss in quantity of ABTS-SNPs during supernatant discarding in the centrifugal recovery process. It has been reported that the radical cation form of ABTS was the main product observed after reacting with laccase, but a degradation product from ABTS was also formed [33]. The decomposition of ABTS during the laccase-ABTS reactions will be a drawback for the application of laccase/ABTS-SNPs system.

\section{Conclusion}

This investigation has demonstrated that ABTS covalently linked to SNPs can be utilized to mediate dye decolorization by laccase. Even though the decolorization efficiency of ABTS-SNPs as mediators is slower than that of the free mediators, the ABTS-SNPs can easily be recovered, regenerated, and reused, therefore improving the efficiency of mediator utilization in LMSs for biotechnological and industrial applications. This process has the potential to alleviate environmental problems caused by the release of free mediators in the wastewater system. Moreover, a large scale application of reusable and immobilized mediators will lower the cost of dye treatment using the laccase mediator systems.

\section{Conflict of Interests}

The authors declare that there is no conflict of interests regarding the publication of this paper.

\section{Acknowledgments}

This research was kindly supported by the Doctoral Innovation Fund of Xinxiang medical University, Nature Science Plan Program (12B180030), from the Education Department of Henan Province and the National Natural Science Foundation of China (no. U1304302).

\section{References}

[1] P. J. Hoegger, S. Kilaru, T. Y. James, J. R. Thacker, and U. Kües, "Phylogenetic comparison and classification of laccase and related multicopper oxidase protein sequences," The FEBS Journal, vol. 273, no. 10, pp. 2308-2326, 2006.

[2] E. I. Solomon, U. M. Sundaram, and T. E. Machonkin, "Multicopper oxidases and oxygenases," Chemical Reviews, vol. 96, no. 7, pp. 2563-2606, 1996.

[3] A. I. Yaropolov, O. V. Skorobogat'ko, S. S. Vartanov, and S. D. Varfolomeyev, "Laccase: properties, catalytic mechanism, and applicability," Applied Biochemistry and Biotechnology, vol. 49, no. 3, pp. 257-280, 1994.

[4] A. Leonowicz, N. S. Cho, J. Luterek et al., "Fungal laccase: properties and activity on lignin," Journal of Basic Microbiology, vol. 41, no. 3-4, pp. 185-227, 2001.

[5] A. M. Mayer and R. C. Staples, "Laccase: new functions for an old enzyme," Phytochemistry, vol. 60, no. 6, pp. 551-565, 2002.

[6] R. C. Minussi, G. M. Pastore, and N. Durán, "Potential applications of laccase in the food industry," Trends in Food Science and Technology, vol. 13, no. 6-7, pp. 205-216, 2002.
[7] O. V. Morozova, G. P. Shumakovich, S. V. Shleev, and Y. I. Yaropolov, "Laccase-mediator systems and their applications: a review," Applied Biochemistry and Microbiology, vol. 43, no. 5, pp. 523-535, 2007.

[8] B. Branchi, C. Galli, and P. Gentili, "Kinetics of oxidation of benzyl alcohols by the dication and radical cation of ABTS. Comparison with laccase-ABTS oxidations: an apparent paradox," Organic and Biomolecular Chemistry, vol. 3, no. 14, pp. 2604-2614, 2005.

[9] C. Johannes and A. Majcherczyk, "Natural mediators in the oxidation of polycyclic aromatic hydrocarbons by laccase mediator systems," Applied and Environmental Microbiology, vol. 66, no. 2, pp. 524-528, 2000.

[10] M. Fabbrini, C. Galli, and P. Gentili, "Comparing the catalytic efficiency of some mediators of laccase," Journal of Molecular Catalysis B: Enzymatic, vol. 16, no. 5-6, pp. 231-240, 2002.

[11] S. Camarero, D. Ibarra, M. J. Martínez, and Á. T. Martínez, "Lignin-derived compounds as efficient laccase mediators for decolorization of different types of recalcitrant dyes," Applied and Environmental Microbiology, vol. 71, no. 4, pp. 1775-1784, 2005.

[12] F. Xu, J. J. Kulys, K. Duke et al., "Redox chemistry in laccasecatalyzed oxidation of N-hydroxy compounds," Applied and Environmental Microbiology, vol. 66, no. 5, pp. 2052-2056, 2000.

[13] Y. Wong and J. Yu, "Laccase-catalyzed decolorization of synthetic dyes," Water Research, vol. 33, no. 16, pp. 3512-3520, 1999.

[14] G. S. Nyanhongo, J. Gomes, G. M. Gübitz, R. Zvauya, J. Read, and W. Steiner, "Decolorization of textile dyes by laccases from a newly isolated strain of Trametes modesta," Water Research, vol. 36, no. 6, pp. 1449-1456, 2002.

[15] P. Brandi, A. D’Annibale, C. Galli, P. Gentili, and A. S. N. Pontes, "In search for practical advantages from the immobilisation of an enzyme: the case of laccase," Journal of Molecular Catalysis B: Enzymatic, vol. 41, no. 1-2, pp. 61-69, 2006.

[16] C. Garcia-Galan, Á. Berenguer-Murcia, R. Fernandez-Lafuente, and R. C. Rodrigues, "Potential of different enzyme immobilization strategies to improve enzyme performance," Advanced Synthesis and Catalysis, vol. 353, no. 16, pp. 2885-2904, 2011.

[17] J. Huang, J.-T. Wang, B. Li et al., "Preparation of organicinorganic nanoparticles composite and their laccase immobilization," Chemical Journal of Chinese Universities, vol. 27, no. 11, pp. 2088-2091, 2006.

[18] Y. Tan, W. Deng, Y. Li et al., "Polymeric bionanocomposite cast thin films with in situ laccase-catalyzed polymerization of dopamine for biosensing and biofuel cell applications," The Journal of Physical Chemistry B, vol. 114, no. 15, pp. 5016-5024, 2010.

[19] B. Palys, A. Bokun, and J. Rogalski, "Poly-o-phenylenediamine as redox mediator for laccase," Electrochimica Acta, vol. 52, no. 24, pp. 7075-7082, 2007.

[20] L. Mendoza, M. Jonstrup, R. Hatti-Kaul, and B. Mattiasson, "Azo dye decolorization by a laccase/mediator system in a membrane reactor: enzyme and mediator reusability," Enzyme and Microbial Technology, vol. 49, no. 5, pp. 478-484, 2011.

[21] K. Rittstieg, A. Suurnäkki, T. Suortti, K. Kruus, G. M. Guebitz, and J. Buchert, "Polymerization of guaiacol and a phenolic $\beta$ $O$-4-substructure by Trametes hirsuta Laccase in the presence of ABTS," Biotechnology Progress, vol. 19, no. 5, pp. 1505-1509, 2003.

[22] A. M. Osman, K. K. Y. Wong, and A. Fernyhough, "The laccase/ ABTS system oxidizes (+)-catechin to oligomeric products," 
Enzyme and Microbial Technology, vol. 40, no. 5, pp. 1272-1279, 2007.

[23] P. Maruthamuthu, L. Venkatasubramanian, and P. Dharmalingam, "A fast kinetic study of formation and decay of 2,2' -azinobis(3-ethylbenzothiazole-6-sulfonate) radical cation in aqueous solution," Bulletin of the Chemical Society of Japan, vol. 60, no. 3, pp. 1113-1117, 1987.

[24] M. Klis, J. Rogalski, and R. Bilewicz, "Voltammetric determination of catalytic reaction parameters of laccase based on electrooxidation of hydroquinone and ABTS," Bioelectrochemistry, vol. 71, no. 1, pp. 2-7, 2007.

[25] M. Chhabra, S. Mishra, and T. R. Sreekrishnan, "Mediatorassisted decolorization and detoxification of textile dyes/dye mixture by cyathus bulleri laccase," Applied Biochemistry and Biotechnology, vol. 151, no. 2-3, pp. 587-598, 2008.

[26] N. Barka, A. Assabbane, A. Nounah, and Y. A. Ichou, "Photocatalytic degradation of indigo carmine in aqueous solution by $\mathrm{TiO}_{2}$-coated non-woven fibres," Journal of Hazardous Materials, vol. 152, no. 3, pp. 1054-1059, 2008.

[27] E.-A. Cho, J. Seo, D.-W. Lee, and J.-G. Pan, "Decolorization of indigo carmine by laccase displayed on Bacillus subtilis spores," Enzyme and Microbial Technology, vol. 49, no. 1, pp. 100-104, 2011.

[28] K. Sadowska, K. Stolarczyk, J. F. Biernat, K. P. Roberts, J. Rogalski, and R. Bilewicz, "Derivatization of single-walled carbon nanotubes with redox mediator for biocatalytic oxygen electrodes," Bioelectrochemistry, vol. 80, no. 1, pp. 73-80, 2010.

[29] R. Bilewicz, E. Nazaruk, K. Zelechowska et al., "Carbon nanotubes chemically derivatized with redox systems as mediators for biofuel cell applications," Biocybernetics and Biomedical Engineering, vol. 31, no. 4, pp. 17-30, 2011.

[30] Z. Zhong, X. Ji, R. Xing et al., "The preparation and antioxidant activity of the sulfanilamide derivatives of chitosan and chitosan sulfates," Bioorganic and Medicinal Chemistry, vol. 15, no. 11, pp. 3775-3782, 2007.

[31] T. Kataoka, T. Iwama, T. Setta et al., "Preparation of sulfonamides from sodium sulfonates: $\mathrm{Ph}_{3} \mathrm{PBr}_{2}$ and $\mathrm{Ph}_{3} \mathrm{PCl}_{2}$ as a mild halogenating reagent for sulfonyl bromides and sulfonyl chlorides," Synthesis, vol. 1998, no. 4, pp. 423-426, 1998.

[32] X. Zhang, B. Pan, B. Wu, W. Zhang, and L. Lv, "A new polymerbased laccase for decolorization of AO7: long-term storage and mediator reuse," Bioresource Technology, vol. 164, pp. 248-253, 2014.

[33] A. Marjasvaara, J. Jänis, and P. Vainiotalo, "Oxidation of a laccase mediator ABTS as studied by ESI-FTICR mass spectrometry," Journal of Mass Spectrometry, vol. 43, no. 4, pp. 470477,2008 . 

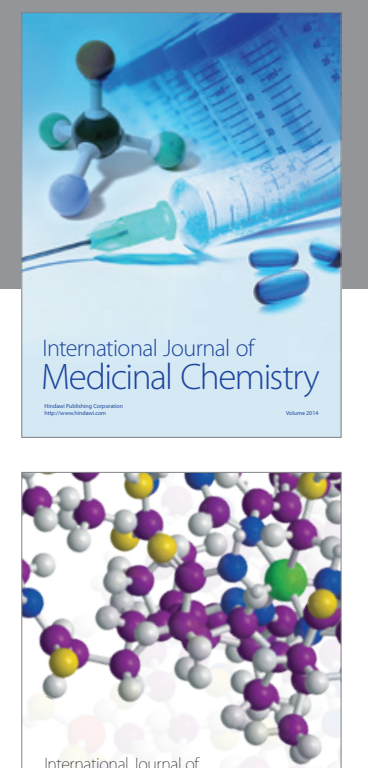

\section{Carbohydrate} Chemistry

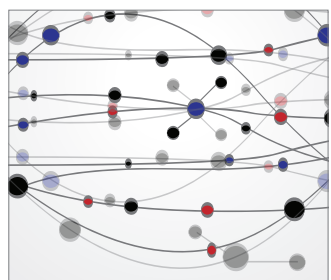

The Scientific World Journal
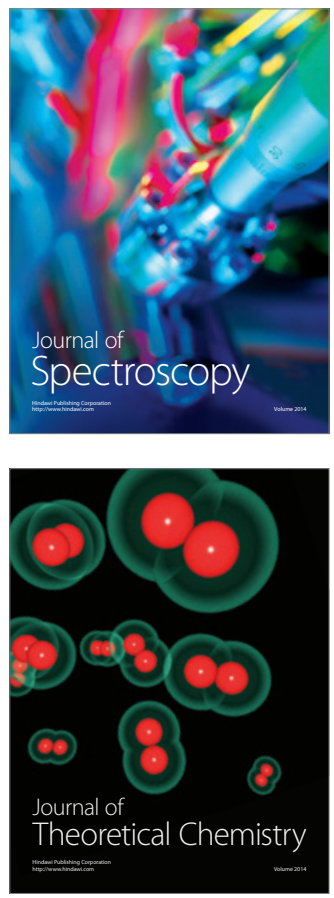
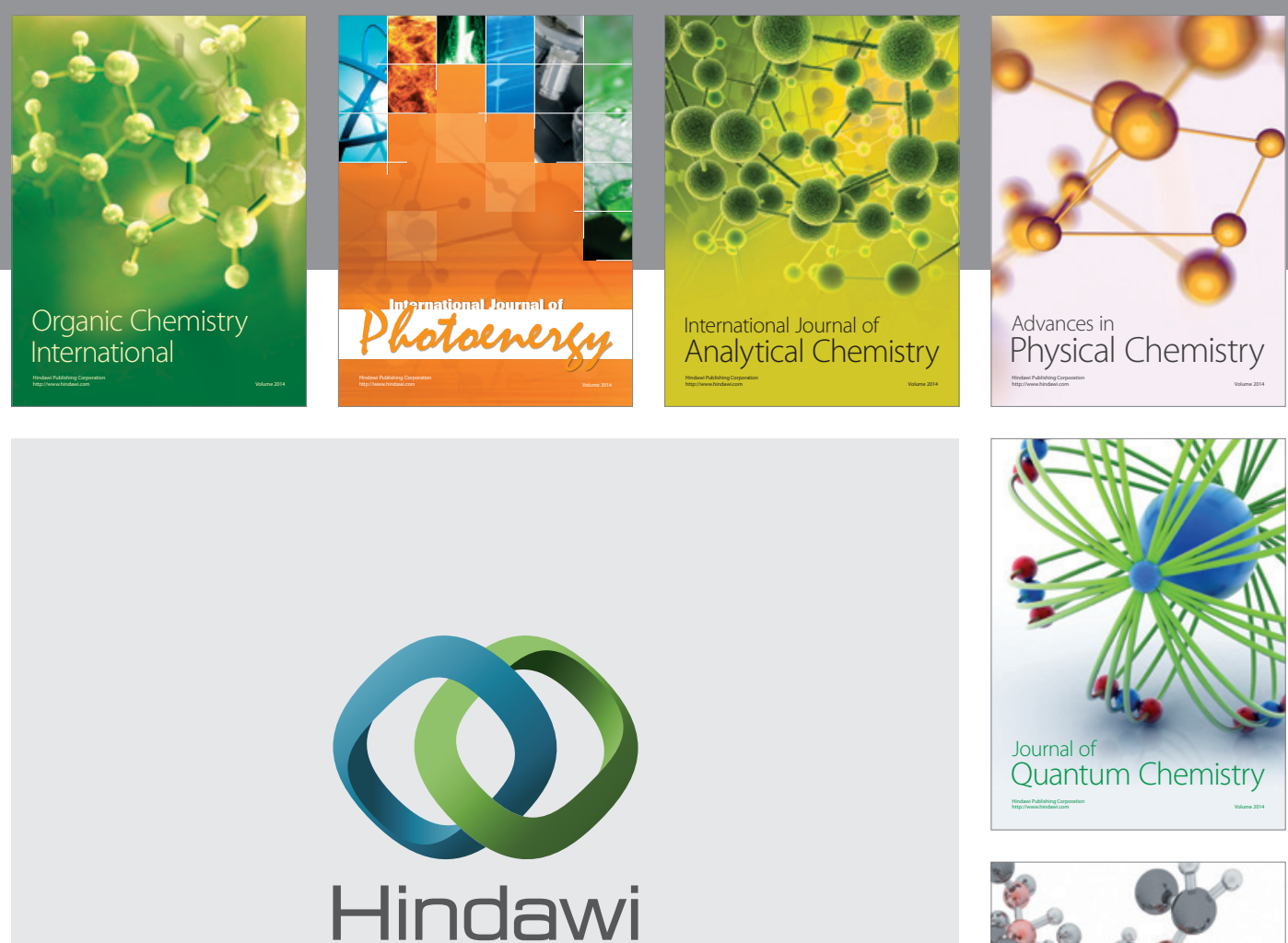

Submit your manuscripts at

http://www.hindawi.com

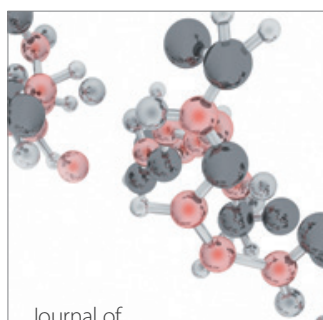

Analytical Methods

in Chemistry

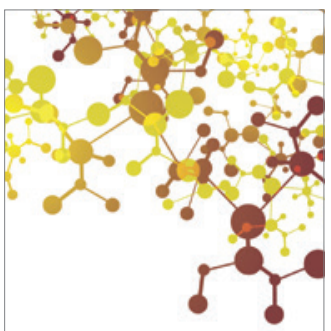

Journal of

Applied Chemistry

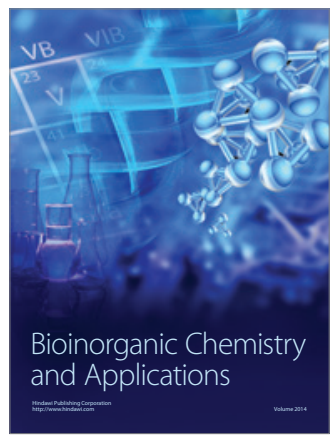

Inorganic Chemistry
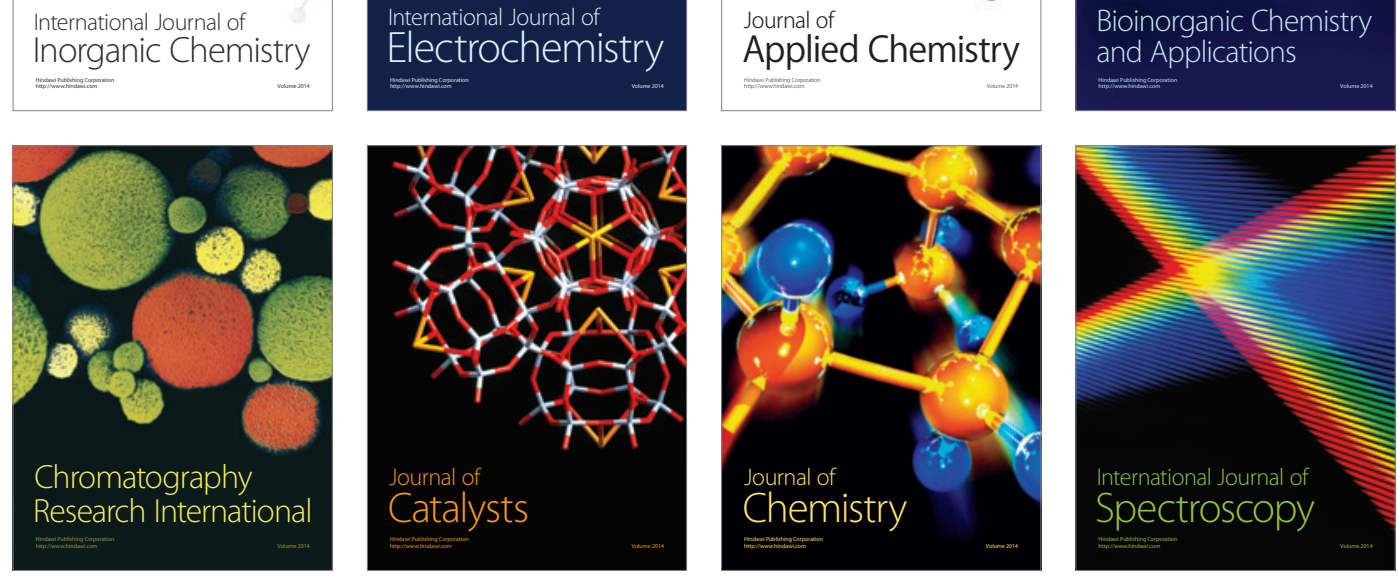